\section{BOOK BRIEFLY NOTED}

\section{Caffey's Pediatric Diagnostic Imaging, 11th ed. 2-Vol. Set}

T.L. Slovis, ed. Oxford, UK: Mosby; 2007, 3536 pages, 3900 illustrations, \$369.00.

Pediatric Diagnostic Imaging is a 2-volume, 23-lb, 3200-page behemoth of radiology information. Edited by Tom Slovis in collaboration with 9 associated editors and 151 contributing authors, this set of books not only defines the entire field of pediatric radiology but shows just how far radiology/diagnostic imaging has progressed during the decades.

The material is vast and complete, covering all organ systems, including sections on radiation effects, prenatal and neonatal imaging (414 pages), neuroradiology (568 pages), the respiratory system (426 pages), the heart and great vessels (281 pages), the abdomen and pelvis (705 pages), the musculoskeletal system (572 pages), and pediatric interventional radiology (121 pages). All of this is supplemented by pages in the front of each volume of multiple color drawings, patient photographs, and color-enhanced images. There is a Website which can be accessed by different individual passwords available inside the front cover. The completeness of this work is emphasized by this Website, which features video clips, selfassessment questions, and a complete set of images. How John Caffey would be amazed not only by all that has taken place since his first edition in 1945 but by how we now access information!

In looking through the text, one finds separate books combined into one 2-volume set. Although the price may seem high (sticker shock), what one is purchasing in truth is 7 books - in that light, this is a bargain.

The neuroradiology section alone challenges any freestanding single neuroradiology text. This section, edited by Eric Faerber, covers the skull ( 80 pages), the face and cranial structures (orbital, nose, sinuses, temporal bone, mandible; 85 pages), the brain (150 pages), the vertebrae (93 pages), and the spine (60 pages). Detailed in every chapter are the embryology and developmental anatomy of the area under question. This is valuable throughout but is particularly so in sinus evaluation and brain mutation. As expected, all major diseases and anomalies are covered in reasonable depth, with appropriate tables/charts and highlighted points, which could be considered key "take-home points." The chapters are abundantly illustrated, with high-quality figures. The bibliography is presented in a very user-friendly manner-viz, instead of annotating points in the text with cited references, the references themselves are listed under categories/subcategories. This makes it easy to look up various citations - that is, by going to the bibliography straight away.

In this reviewer's opinion, no department or hospital library should be without this 2-volume set, and every serious pediatric radiologist should own a personal copy.

DOI 10.3174/ajnr.A1024 